\title{
Peristaltic Flow of a Sisko Fluid over a Convectively Heated Surface with Viscous Dissipation
}

\author{
Shaheen $\mathrm{A}^{1 *}$ and Asjad $\mathrm{MI}^{2}$ \\ ${ }^{1}$ Department of Mathematics, Comsat Institute of Science and Technology, Park Road, Tarlai Kalan, Islamabad, Pakistan \\ ${ }^{2}$ Department of Mathematics, University of Management and Technology, Block C-Il, Johar Town, Lahore, Pakistan
}

\begin{abstract}
In the current paper, we have analyzed the peristaltic flow of non-Newtonian Sisko fluid with convective boundary conditions in a uniform tube. The effects of viscous dissipation are also taken into account. The governing equations of non-Newtonian fluid along with heat and nanoparticles are modelled and simplified by using low Reynolds number and long wavelength assumptions. The velocity equation is solved by utilizing the homotopy perturbation technique while the exact solutions are computed for temperature and concentration equations. The solutions depend on Brinkman number $\left(B_{k}\right)$ and Magnetohydrodynamics $(M)$. The obtained expressions for the velocity, temperature and concentration profiles are plotted and the impact of various physical parameters are investigated for different peristaltic waves.
\end{abstract}

Keywords: Sisko fluid; Peristaltic flow; Viscous-dissipation effects; Convective boundary condition; Exact solution.

\section{Introduction}

A process of symmetrical contraction and expansion of progressive waves on the walls of the channel which mix and transport fluid in a channel is termed as peristalsis. In several procedures of physiology and engineering, peristaltic flow concerns are broadly encountered in channel or tube. The applications of peristalsis covers swallowing food through the esophagus, urine transportation from kidney to bladder, assessment of chyme in gastrointestinal tract, ovum movement in the female fallopian tube, vasomotion of narrow blood vessels, movement of spermatozoa in human reproductive tract and water movement from ground to above branches of grown-up trees [1-4].

Peristaltic flows have many biological and industrial applications such as blood pumps in heart, lung machines and transportation of mordant fluids. For the viscous fluids, Lithium and Sharpio presented the earliest theoretical and experimental models for peristaltic transport $[5,6]$. Peristalsis during male reproductive system was examined experimentally and numerically by Srivastava, Gupta [7], Guha et al. [8] and Batra [9], where a peristaltic flow has been modelled in the vas deferens by considering it to be a non-uniform tube. Many modern mechanical procedures have been investigated on the primary of the peristaltic pumping for transporting fluids without internal moving parts, for example, the blood pump in the heart, lung machine and the peristaltic transport of noxious fluid in the nuclear industry. It was also clarified that in the case of hyperthermia, the tissue can be destroyed when heated upto $42^{\circ} \mathrm{C}-45^{\circ} \mathrm{C}$. A mathematical model of peristaltic hydromagnetic flow in a tube for the Johnson-Segalman fluid has been studied by Hayat and Ali [10]. Hydromagnetic flow of fluid in a uniform pipe with variable thickness was investigated by Hakeem et al. [11]. Nadeem and Akbar [12] have studied the peristaltic wave of a non-Newtonian fluid in a non-uniform inclined pipe. Peristaltic transportation of a non-Newtonian fluid in an inclined channel was discussed by Vajravelu et al. [13].

Study of peristaltic flow in the presence of magnetic field has also achieved a lot of importance in daily life and engineering sciences. Some previous papers dealing with MHD flows of peristaltic are discussed [14-16]. Effects of MHD on the peristaltic flows for different modes of heat transfer like conduction, convection and radiations are reported [17-21]. For other studies regarding MHD flows, are can consult [2224]. The rate of heat transfer is dependent on the temperatures of the systems and the properties of the prevailing medium through which the heat is transferred. Different authors have discussed $[25,26]$ the effect of force on the heat convection and mass transfer. Study of peristaltic flow in the presence of magnetic field has also achieved a lot of importance in daily life and engineering sciences. Some previous papers dealing with MHD flows of peristaltic are discussed [14-16]. Effects of MHD on the peristaltic flows for different modes of heat transfer like conduction, convection and radiations [17-21]. For other studies regarding MHD flows [22-24].

Since the first investigation done by the Choi [27], the study of nanofluids have attracted the attention of many researchers due to its tremendous applications in various fields of life such as biomedical devices, treatment of tumor, nuclear reactor, microchips, cooling, radiators and nanomedicines etc. Only few researches are available on the peristaltic flows of nanofluids [28-33]. Motivated by the above work the aim of present findings is to treatise the Sisko fluid and viscous dissipation effects with convective boundary conditions. The problem of the two-dimensional motion of non-Newtonian fluid inside a uniform horizontal with convective boundary condition is discussed. The governing equations for conservation of mass, momentum and heat equation have been simplified throughout the assumption of low Reynolds number and long wave length approximation. The modelled equations are solved analytically by homotopy perturbation method [34]. The physical features of pertinent parameters are discussed through graphs.

*Corresponding author: Shaheen A, Department of Mathematics, Comsa Institute Of Science And Technology, Park Road, Tarlai Kalan, Islamabad 45550 Pakistan, Tel:+92 51 9247000; E-mail: shaheenaqila@gmail.com

Received December 26, 2018; Accepted January 03, 2018; Published February 16,2018

Citation: Shaheen A, Asjad MI (2018) Peristaltic Flow of a Sisko Fluid over a Convectively Heated Surface with Viscous Dissipation. J Appl Computat Math 7: 402. doi: 10.4172/2168-9679.1000402

Copyright: @ 2018 Shaheen A, et al. This is an open-access article distributed under the terms of the Creative Commons Attribution License, which permits unrestricted use, distribution, and reproduction in any medium, provided the original author and source are credited. 
This paper is structured as follows: In this paper, we discuss the details of the mathematical formulation. This describes the proposed solution methodologies for the solution of the governing partial differential equations. This presented the analytical results and discussions. Finally, in the paper is concluded with a discussion on the results.

\section{Mathematical Formulation}

We have analyzed the peristaltic flow of an incompressible Sisko fluid in a uniform tube. The flow in the tube is sinusoidal wave along the wall with constant speed $c$. The wall of the tube are defined as,

$$
\bar{H}=a+b \sin \left[\frac{2 \pi}{\lambda}(\bar{Z}-c t)\right]
$$

The geometry of the problem is shown in Figure 1 where $a$ is the radius of the tube at inlet.

$\mathrm{b}$ is the wave amplitude, $\lambda$ represent the wavelength, $\mathrm{c}$ is the propagation speed and $t$ is the time.

The fundamental equations of continuity, momentum, nanoparticle concentration are

$$
\begin{aligned}
& \frac{\partial \bar{U}}{\partial \bar{R}}+\frac{\bar{U}}{\bar{R}}+\frac{\partial \bar{W}}{\partial \bar{Z}}=0 \\
& \rho\left(\frac{\partial}{\partial t}+\bar{U} \frac{\partial}{\partial \bar{R}}+\bar{W} \frac{\partial}{\partial \bar{Z}}\right) \bar{U}=-\frac{\partial \bar{P}}{\partial \bar{R}}+\frac{1}{\bar{R}} \frac{\partial}{\partial \bar{R}}\left(\bar{R} \bar{S}_{\bar{R} \bar{R}}\right)+\frac{\partial}{\partial \bar{Z}}\left(\bar{S}_{\bar{R} \bar{Z}}\right)-\frac{\bar{S}_{\overline{\theta \bar{\theta}}}}{\bar{R}}(3) \\
& \rho\left(\frac{\partial}{\partial t}+\bar{U} \frac{\partial}{\partial \bar{R}}+\bar{W} \frac{\partial}{\partial \bar{Z}}\right) \bar{W}=-\frac{\partial \bar{P}}{\partial \bar{R}}+\frac{1}{\bar{R}} \frac{\partial}{\partial \bar{R}}\left(\bar{R} \bar{S}_{\bar{R} \bar{Z}}\right)+\frac{\partial}{\partial \bar{Z}}\left(\bar{S}_{\overline{Z Z}}\right)-\sigma B_{0}^{2} \bar{W}(4) \\
& \rho c_{\rho}\left(\frac{\partial}{\partial \bar{t}}+\bar{U} \frac{\partial}{\partial \bar{R}}+\frac{\partial}{\partial \bar{Z}}\right) \bar{T}=\bar{S}_{R \bar{R}} \frac{\partial \bar{U}}{\partial \bar{R}}+\bar{S}_{\bar{R}} \frac{\partial \bar{W}}{\partial \bar{R}}+\bar{S}_{\overline{R Z}} \frac{\partial \bar{U}}{\partial \bar{Z}}+\bar{S}_{Z Z} \frac{\partial \bar{U}}{\partial \bar{R}}+\bar{S}_{\nexists \bar{\theta}} \overline{\bar{R}}+\bar{K}\left(\frac{\partial^{2} \bar{T}}{\partial \bar{R}^{2}}+\frac{1}{\overline{\bar{R}}} \frac{\partial \bar{T}}{\partial \bar{R}}+\frac{\partial^{2} \bar{T}}{\partial \bar{Z}^{2}}\right)(5) \\
& \left(\frac{\partial}{\partial \bar{t}}+\bar{U} \frac{\partial}{\partial \bar{R}}+\bar{W} \frac{\partial}{\partial \bar{Z}}\right) \bar{C}=D\left(\frac{\partial^{2} \bar{C}}{\partial \bar{R}^{2}}+\frac{1}{\bar{R}} \frac{\partial \bar{C}}{\partial \bar{R}}+\frac{\partial^{2} \bar{C}}{\partial \bar{Z}^{2}}\right)+\frac{D \bar{k}_{t}}{\bar{T}_{0}}\left(\frac{\partial^{2} \bar{T}}{\partial \bar{R}^{2}}+\frac{1}{\bar{R}} \frac{\partial \bar{T}}{\partial \bar{R}}+\frac{\partial^{2} \bar{T}}{\partial \bar{Z}^{2}}\right)(6)
\end{aligned}
$$

The transformation relation between the two Coordinate frames are

$\bar{r}=\bar{R}, \bar{z}=\bar{Z}-c \bar{t}$
$\bar{u}=\bar{U}, \bar{w}=\bar{W}-c$

The corresponding boundary conditions are defined as

$$
\begin{aligned}
& \frac{\partial \bar{W}}{\partial \bar{R}}=0, \frac{\partial \bar{T}}{\partial \bar{R}}=0, \frac{\partial \bar{C}}{\partial \bar{R}}=0 \quad \text { at } \bar{R}=0, \\
& \bar{W}=0, \mathrm{~K} \frac{\partial \bar{T}}{\partial \bar{R}}=-\eta\left(\bar{T}-\bar{T}_{0}\right), \bar{C}=\bar{C}_{0} \text { at } \bar{R}=\bar{H}=a+b \sin \left[\frac{2 \pi}{\lambda}(\bar{Z}-c \bar{t})\right]
\end{aligned}
$$

The constitutive equation for a Sisko fluid model is defined as $\bar{S}=\left[a_{1}+b_{1}(\sqrt{\bar{\Pi}})^{n-1}\right] \bar{A}_{1}$,

$\bar{A}_{1}=\bar{L}+\bar{L}^{T}, \bar{L}=\nabla \bar{V}, \bar{\Pi}=\frac{1}{2} \operatorname{tr} \bar{A}_{1}^{2}$

The non-dimensional constants are known as

$$
\begin{gathered}
R=\frac{\bar{R}}{a}, r=\frac{\bar{r}}{a}, Z=\frac{\bar{Z}}{\lambda}, W=\frac{\bar{W}}{c}, \mathrm{w}=\frac{\bar{w}}{c}, S=\frac{a \bar{S}}{c \mu_{0}}, \\
U=\frac{\lambda \bar{U}}{a c}, u=\frac{\lambda \bar{u}}{a c}, \mathrm{t}=\frac{c_{1} \bar{t}}{\lambda}, \lambda_{1}=\frac{\epsilon_{1} c_{1}}{a}, \lambda_{2}=\frac{\epsilon_{2} c_{1}}{a}, \\
R_{e}=\frac{a c_{1} \rho}{\mu_{0}}, \delta=\frac{a}{\lambda}, h=\frac{\bar{h}}{a}=1+\in \sin (2 \pi z), P_{r}=\frac{\pi_{0} c_{p}}{k}, \\
\mathrm{E}_{c}=\frac{c^{2}}{c_{p} T_{0}}, \theta=\frac{\bar{T}-\bar{T}_{0}}{\bar{T}_{0}}, \Pi=\frac{a \bar{\Pi}}{c}, \alpha=\frac{k}{(\rho c) f}, p=\frac{a^{2} \bar{p}}{c_{1} \lambda \mu_{0}}, \\
S_{T}=\frac{\rho D k_{T} \bar{T}_{0}}{\mu T_{0} \bar{C}_{0}}, S_{H}=\frac{\mu}{D_{\rho}}, \sigma=\frac{\bar{C}-\bar{C}_{0}}{\bar{C}_{0}}, M=\sqrt{\frac{\sigma}{\mu} B_{0} a^{2}} .
\end{gathered}
$$

We suppose for small Reynolds number $R e<<1$ and by the Longwavelength approximation $\delta<<1$ the flow inside the passage is very slow. Therefore, neglecting the non-inertial terms we get

$$
\begin{aligned}
& 0=\frac{\partial u}{\partial r}+\frac{u}{r}+\frac{\partial w}{\partial z}, \\
& 0=\frac{\partial p}{\partial r}, \\
& 0=-\frac{\partial p}{\partial z}+\frac{1}{r} \frac{\partial}{\partial r}\left(r S_{r z}\right)-M^{2}(w+1), \\
& 0=\frac{1}{r} \frac{\partial}{\partial r}\left(r \frac{\partial \theta}{\partial r}\right)+B_{k} \frac{\partial w}{\partial r}\left(S_{r z}\right) \\
& 0=\frac{1}{S_{H}} \frac{1}{r} \frac{\partial}{\partial r}\left(\mathrm{r} \frac{\partial \sigma}{\partial r}\right)+\mathrm{S}_{T} \frac{1}{r} \frac{\partial}{\partial r}\left(\mathrm{r} \frac{\partial \theta}{\partial r}\right) \\
& \frac{\partial w}{\partial r}=0, \frac{\partial \theta}{\partial r}=0, \frac{\partial \sigma}{\partial r}=0 \quad \text { at } r=0, \\
& w=-1, \frac{\partial \theta}{\partial r}+k \theta=0, \sigma=0 \text { at } r=h=1+\in \sin (2 \pi z)
\end{aligned}
$$

where $M$ is the Hartmann number, $b$ represent the sisko parameter and $\epsilon$ the amplitude ratio $(\epsilon=\mathrm{a} / \mathrm{b})$, Soret number is $S_{T}$, Schmidt number is the $S_{H}$ and Brinkman number is

$B_{k}$

where

$$
\begin{aligned}
& S_{r r}=2 \delta\left[1+b\left(\frac{\partial w}{\partial r}\right)^{n-1}\right] \frac{\partial u}{\partial r} \\
& S_{r z}=\left[1+b\left(\frac{\partial w}{\partial r}\right)^{n-1}\right]\left(\frac{\partial u}{\partial z} \delta^{2}+\frac{\partial w}{\partial r}\right) \\
& S_{z z}=2 \delta\left[1+b\left(\frac{\partial w}{\partial r}\right)^{n-1}\right] \frac{\partial w}{\partial r} .
\end{aligned}
$$

Finally, in simplified form above equation can be written as

$$
\begin{aligned}
& \frac{\partial p}{\partial r}=0 \\
& \frac{\partial p}{\partial z}=\frac{1}{r} \frac{\partial}{\partial r}\left(r\left[1+b\left(\frac{\partial w}{\partial r}\right)^{n-1}\right] \frac{\partial w}{\partial r}\right)-M^{2}(w+1)
\end{aligned}
$$

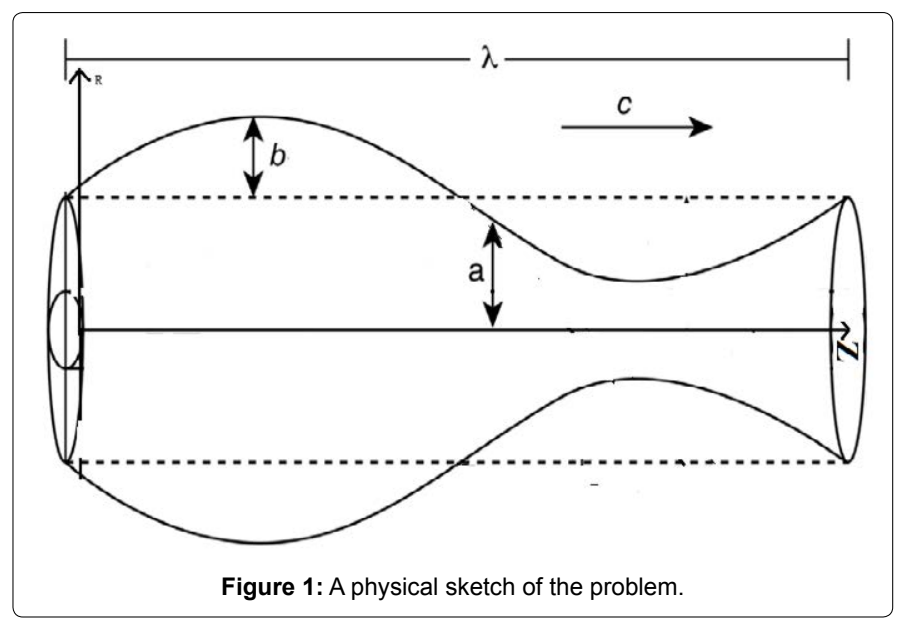




$$
\begin{aligned}
& \frac{1}{r} \frac{\partial}{\partial r}\left(r \frac{\partial \theta}{\partial r}\right)+B_{k} \frac{\partial w}{\partial r}\left(S_{r z}\right)=0 \\
& \frac{1}{S_{H}} \frac{1}{r} \frac{\partial}{\partial r}\left(r \frac{\partial \sigma}{\partial r}\right)+S_{T} \frac{1}{r} \frac{\partial}{\partial r}\left(r \frac{\partial \theta}{\partial r}\right)=0
\end{aligned}
$$

The corresponding boundary conditions are defined as

$$
\begin{aligned}
& \frac{\partial w}{\partial r}=0, \frac{\partial \theta}{\partial r}=0, \frac{\partial \sigma}{\partial r}=0 \quad \text { at } r=0, \\
& w=-1, \frac{\partial \theta}{\partial r}+k \theta=0, \sigma=0 \quad \text { at } r=h=1+\in \sin (2 \pi z)
\end{aligned}
$$

\section{Solution Methodology}

Since the resulting equation of the above boundary value problem is non-linear. Thus it is appropriate homotopy perturbation method to solve eqn.(16), The homotopy perturbation method for eqn. (16) is defined as

$$
H(q, w)=L(w)-L\left(w_{10}\right)+q\left[\frac{b}{r}\left(\frac{\partial w}{\partial r}\right)^{n}+n b\left(\frac{\partial w}{\partial r}\right)^{n-1}\left(\frac{\partial^{2} w}{\partial r^{2}}\right)+-M^{2}(W+1)-\frac{\partial p}{\partial z}\right](16)
$$

We choose linear operator $L=\frac{1}{r} \frac{\partial}{\partial r}\left(r \frac{\partial}{\partial r}\right)$ and initial guess which satisfy the required boundary conditions are

$$
\begin{aligned}
& w_{10}(r, z)=-1+p_{0}\left[\frac{r^{2}-h^{2}}{4}\right] \\
& H(q, w)=L(w)-L\left(w_{10}\right)+q L\left(\mathrm{w}_{10}\right)+q\left[\frac{b}{r}\left(\frac{\partial w}{\partial r}\right)^{2}+2 b\left(\frac{\partial w}{\partial r}\right)\left(\frac{\partial^{2} w}{\partial r^{2}}\right)+-M^{2}(W+1)-\frac{\partial p}{\partial z}\right]
\end{aligned}
$$

where initial guess is $w_{10}$ and embedding constant is $q \in[0 ; 1]$. According to HPM, we solve

$$
\begin{aligned}
& w(r, q)=w_{0+} q w_{1+} q^{2} w_{2+} q^{3} w_{3+} \cdots \\
& p(r, q)=p_{1+} q p_{2+} q^{2} p_{3+} q^{3} p_{4+} \cdots
\end{aligned}
$$

The velocity field for $q \rightarrow 1$ takes the form

$$
w=-1+\left(\frac{r^{2}-h^{2}}{4}\right) \frac{d p}{d z}+A_{1}\left(r^{2}-h^{2}\right)+A_{2}\left(r^{3}-h^{3}\right)+A_{3}\left(r^{4}-h^{3}\right)+A_{4}\left(r^{5}-h^{5}\right)+A_{5}\left(r^{6}-h^{6}\right)+A_{6}\left(r^{7}-h^{7}\right)
$$

The exact solutions for the temperature and concentration satisfying the relative boundary conditions are directly written as:

$$
\begin{aligned}
& \theta=A_{7}\left(r^{4}-h^{4}\right)+A_{8}\left(r^{4}-h^{4}\right)+A_{9}\left(r^{4}-h^{4}\right)+A_{10}\left(r^{5}-h^{5}\right)+A_{11}\left(r^{5}-h^{5}\right)+ \\
& A_{12}\left(\mathrm{r}^{5}-\mathrm{h}^{5}\right)+\mathrm{A}_{13}\left(r^{5}-h^{5}\right)+A_{14}\left(r^{5}-h^{5}\right)+A_{15}\left(r^{5}-h^{5}\right)+A_{16}\left(r^{6}-h^{6}\right)+ \\
& A_{17}\left(r^{6}-h^{6}\right)+A_{18}\left(r^{6}-h^{6}\right)+A_{19}\left(r^{6}-h^{6}\right)+A_{20}\left(r^{6}-h^{6}\right)+A_{21}\left(r^{6}-h^{6}\right)+ \\
& A_{22}\left(r^{7}-h^{7}\right)+A_{23}\left(r^{7}-h^{7}\right)+A_{24}\left(r^{7}-h^{7}\right)+A_{25}\left(r^{7}-h^{7}\right)+A_{26}\left(r^{7}-h^{7}\right)+A_{27}\left(r^{7}-h^{7}\right)+ \\
& A_{28}\left(r^{8}-h^{8}\right)+A_{29}\left(r^{8}-h^{8}\right)+A_{30}\left(r^{8}-h^{8}\right)+A_{31}\left(r^{8}-h^{8}\right)+ \\
& A_{32}\left(r^{9}-h^{9}\right)+A_{33}\left(r^{9}-h^{9}\right)+A_{34}\left(r^{9}-h^{9}\right)+A_{35}\left(r^{10}-h^{10}\right)+A_{36}\left(r^{11}-h^{11}\right)+ \\
& \left(\frac{-B_{K} h^{3}}{16}-\frac{1}{40} b B_{k} h^{4}+\frac{1}{48} M B_{k} h^{5}+\frac{27}{2240} b B_{k} h^{6} M_{p 0}+\frac{1}{20} b B_{k} h^{4} p_{0}^{2}+\frac{1}{32} b^{2} B_{k} h^{5} p_{0}^{2}\right. \\
& \frac{1}{k}+\frac{11}{6144} M^{2} B_{k} h^{7} p_{0}^{2}-\frac{9}{1120} b B_{k} h^{6} M p_{0}^{3}-\frac{5}{512} b^{2} B_{k} h^{7} M p_{0}^{3}-\frac{1}{96} b^{2} B_{k} h^{5} p_{0}^{4}+\frac{3}{224} b^{3} B_{k} h^{6} p_{0}^{4} \\
& +\frac{1}{1280} b^{2} B_{k} h^{4} M^{2} p_{0}^{4}+\frac{11}{5376} b^{3} B_{k} h^{8} M p_{0}^{5}+\frac{1}{512} b^{4} B_{k} h^{7} p_{0}^{6} \\
& \sigma=A_{37}\left(r^{4}-h^{4}\right)+A_{38}\left(r^{4}-h^{4}\right)+A_{39}\left(r^{5}-h^{5}\right)+A_{40}\left(r^{5}-h^{5}\right)+A_{41}\left(r^{6}-h^{6}\right) \\
& +A_{42}\left(r^{6}-h^{6}\right)+A_{43}\left(r^{6}-h^{6}\right)+A_{44}\left(r^{7}-h^{7}\right)+A_{45}\left(r^{7}-h^{7}\right)+A_{46}\left(r^{7}-h^{7}\right) \\
& +A_{47}\left(r^{8}-h^{8}\right)+A_{48}\left(r^{8}-h^{8}\right)+A_{49}\left(r^{8}-h^{8}\right)+A_{50}\left(r^{9}-h^{9}\right)+A 51\left(r^{9}-h^{9}\right)+ \\
& A_{52}\left(r^{10}-h^{10}\right)+A_{53}\left(r^{11}-h^{11}\right) \text {. } \\
& \frac{d p}{d z}=\frac{16}{-h^{4}}\left[F+A_{54}\right]
\end{aligned}
$$

Using Mathematica the constants $A_{1}, A_{2}, \ldots, A_{54}$ can be calculated from eqn. (22).

Flow rate in the dimensionless form can be written as

$$
\Delta p=\int_{0}^{1}\left(\frac{d p}{d z}\right) \mathrm{dz}
$$

The pressure rise $\Delta p$ can be written as

$$
\Delta p=\int_{0}^{1}\left(\frac{d p}{d z}\right) \mathrm{d} z
$$

Velocities in terms of stream functions are defined as

$u=-\frac{1}{r}\left(\frac{\partial \psi}{\partial z}\right), \mathrm{w}=\frac{1}{r}\left(\frac{\partial \psi}{\partial z}\right)$.

For the flow analysis, we have considered three waveforms, namely, sinusoidal wave, trapezoidal wave and mulltisinusoidal wave. The dimensionless equations can be written as

\section{Sinusoidal wave}

$\mathrm{h}(\mathrm{z})=1+\in \sin (2 \pi \mathrm{z})$

\section{Multisinusoidal wave}

$\mathrm{h}(\mathrm{z})=1+\in \sin (2 \mathrm{~m} \pi \mathrm{z})$

\section{Trapizoidal wave}

$$
\mathrm{h}(z)=1+\in\left\{\frac{32}{\pi^{2}} \frac{4}{\pi} \sum_{n=1}^{\infty} \frac{\sin \frac{\pi}{8}(2 n-1)}{(2 n-1)^{2}} \sin (2 \pi(2 n-1) \mathrm{z})\right\}
$$

\section{Square wave}

$$
\left.\mathrm{h}(z)=1+\in \frac{4}{\pi} \sum_{n=1}^{\infty} \frac{\cos \frac{\pi}{8}(2 n-1)}{(2 n-1)^{2}} \sin (2 \pi(2 \mathrm{n}-1) \mathrm{z})\right\}
$$

\section{Results and Discussions}

In this section, we have analyzed the solution for physiological breakdown of Sisko fluid model with convective boundary condition in a uniform tube through graphs. We have presented the solution attained by HPM by framing velocity, pressure rise, pressure gradient, temperature, concentration and streamline graphs for diverse values of the parameters $n$ (power law index) and $b$ (fluid parameter) and $M$ (magnetic hydrodynamics), $\kappa$ (Biot number), $B_{k}$ (Brinkman number), $S_{T}$ (Soret number), $S_{H}$ (Schmidt number) respectively. Figures 2-5 show that with the increase in $b, B_{k}, M, \kappa$ temperature profile increases. From figure 5 it is seen that with the increase in $\kappa$ temperature profile decreases. Figures 6-9 show that with the increase in $b, B, M, S_{T}$ concentration profile increases. From Figure 10 it is seen that with the increase in $S_{H}$ concentration profile decreases. Figure 11 shows that increases the value of $M$ while the velocity profile in the centre of the tube decreases as well as it gets opposite behaviour nearest of the tube or near the peristaltic wave. Figures 12 and 13 show that shear stress gets increasing function in the region $(0.5 \leq r \leq 0)$ whereas it get opposite behaviour in the region $(-1 \leq r$ $\leq-0.49$ ). Figure 14-19 show the pressure rise (versus flow rate) for diverse value of $M, b$. From Figure 14, it is depicted that by increasing value of $M$ pressure rise increasing in the region $(Q \in[-2,0.5])$ whereas reflux occur in the last. The retrograde pumping region can also be seen in Figure 14 when $Q<0$ and $\Delta p>0$ and free pumping region can be seen when $Q=0$ and $\Delta p=0$. Moreover, augmented pumping region can also be seen in Figure 14 when $Q>0$ and $\Delta p<0$. From Figures 16 and 18 it is seen that with the increase in pressure rise decreases in the region $(Q \in[-2,-0.4])$ whereas reflux occur in the last. Figures 15, 17 and 19 show the friction force for diverse values of $M, b$, From these figures it is depicted that the friction forces have an opposite behavior as compared to pressure rise.

Figures 20-22 describe the behavior of pressure gradient for different waveforms like Sinusoidal, multisinusoidal, trapezoidal. Figure 20 describe that increasing value of the pressure gradient decreases in the region $(0 \leq Z \leq 0.5)$ and increases in the region $(0.6 \leq$ $Z \leq 1)$ and reflux occur in the region $(1.1 \leq Z \leq 1.5)$. 


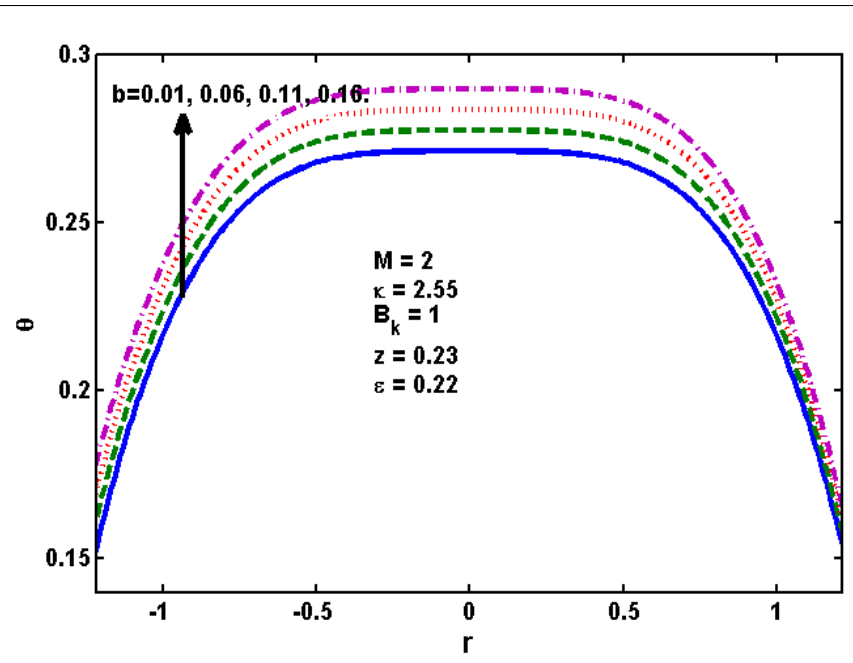

Figure 2: Effect of $b$ on $\theta$.

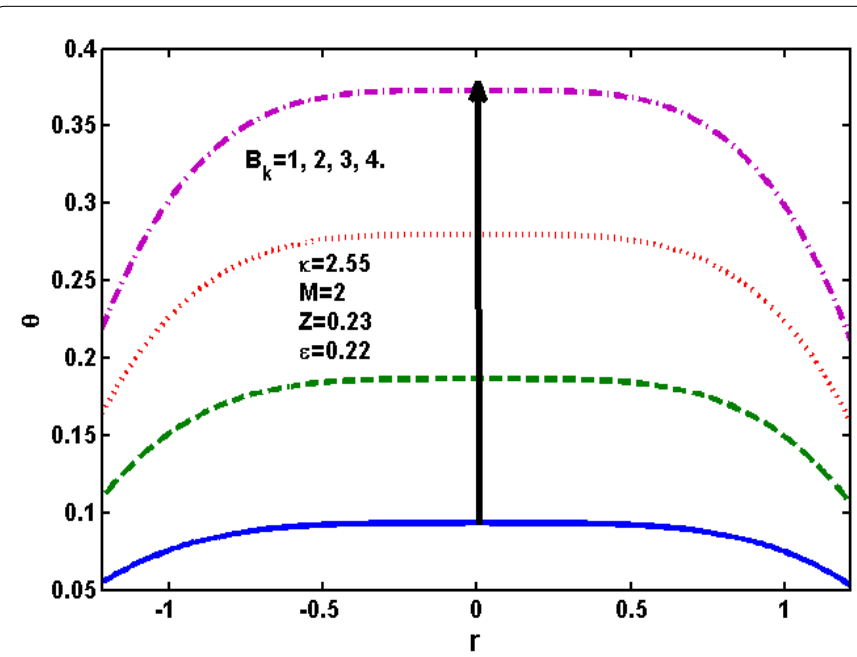

Figure 3: Effect of $B_{k}$ on $\theta$

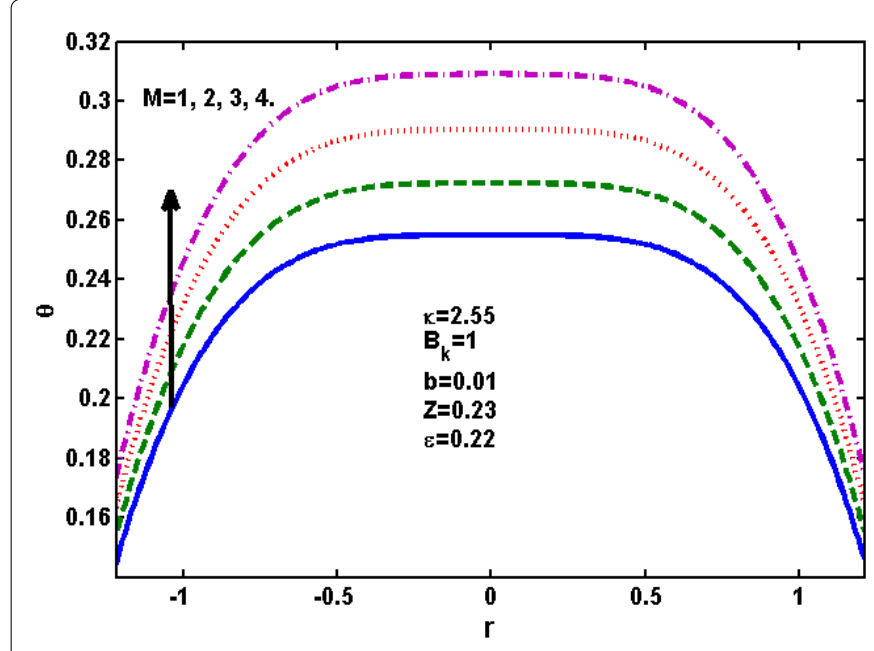

Figure 4: Effect of $M$ on $\theta$.
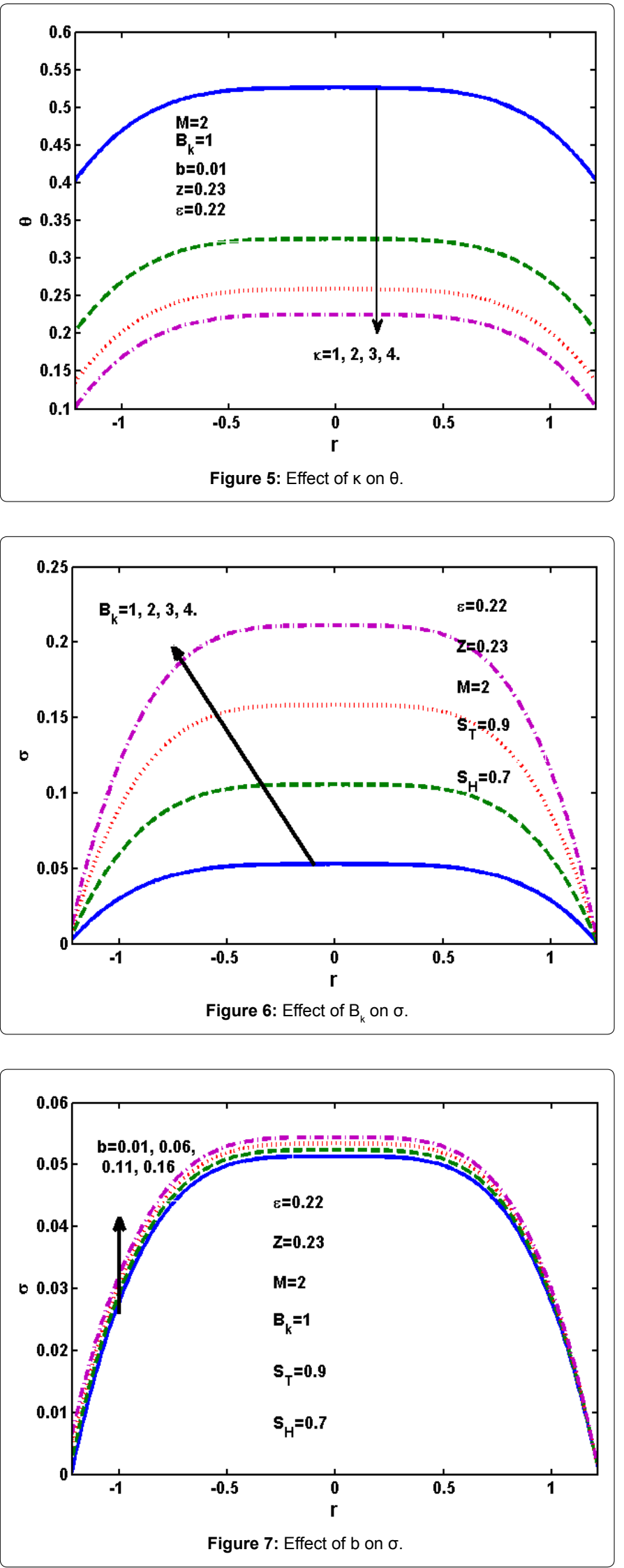


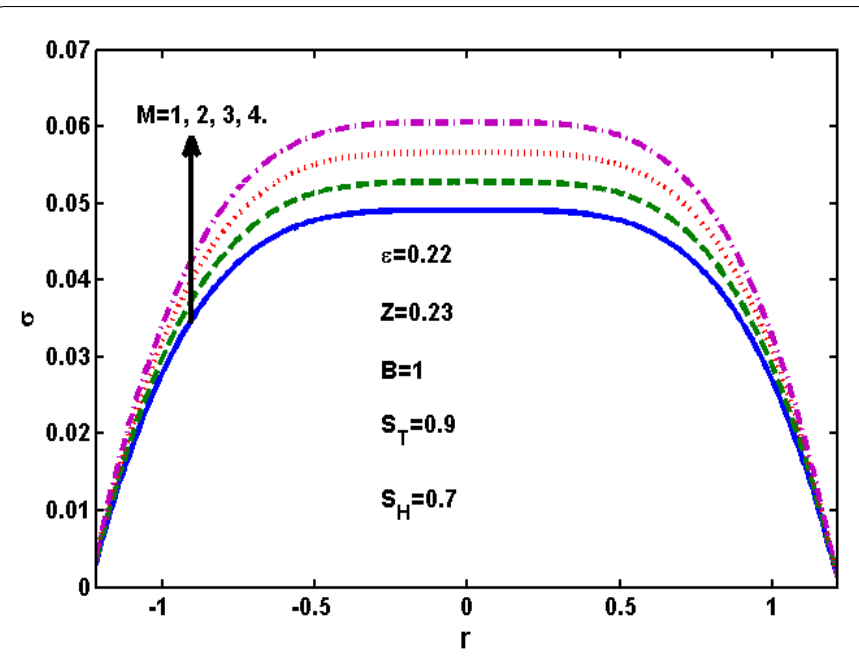

Figure 8: Effect of $M$ on $\sigma$.

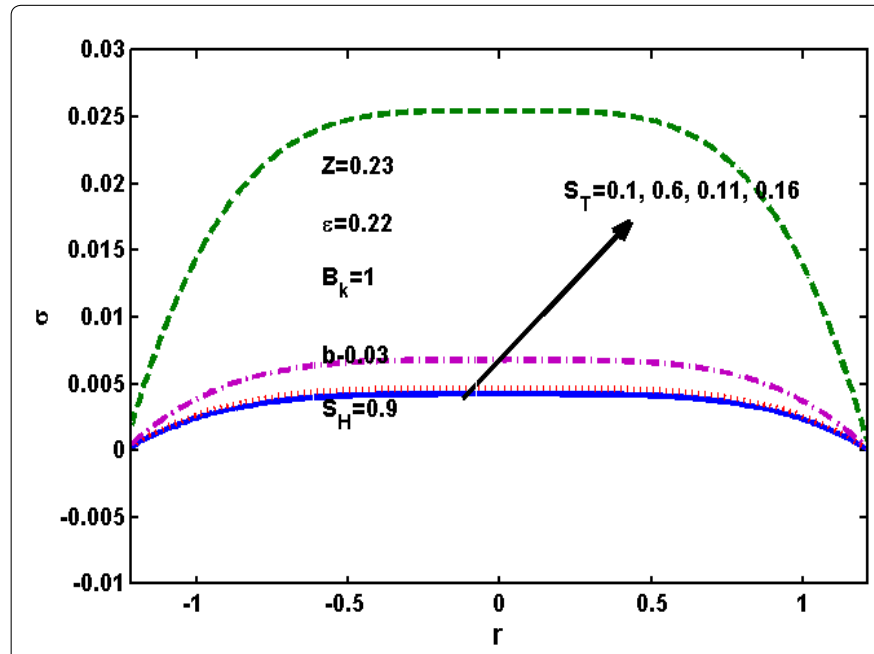

Figure 9: Effect of $S_{T}$ on $\sigma$

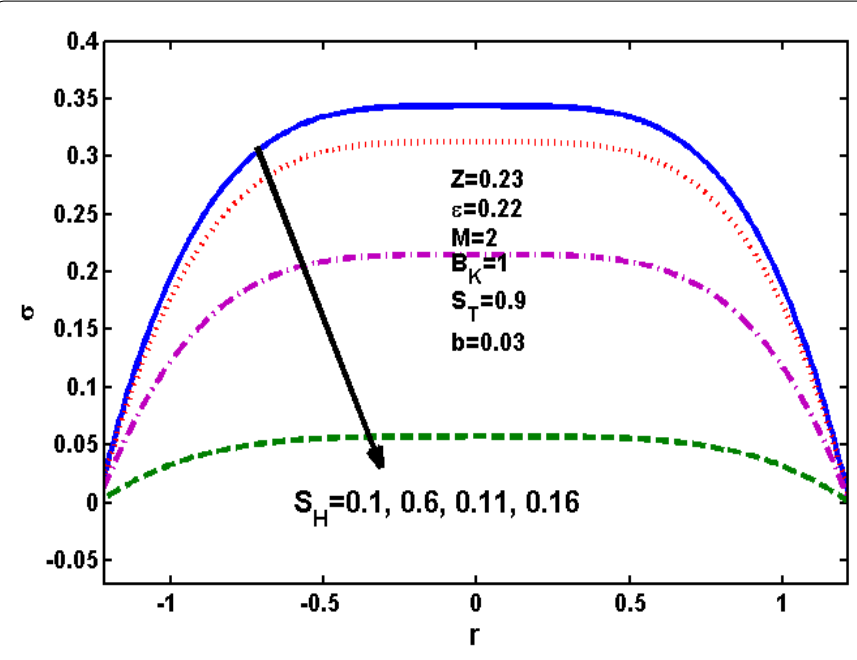

Figure 10: Effect of $S_{H}$ on $\sigma$.
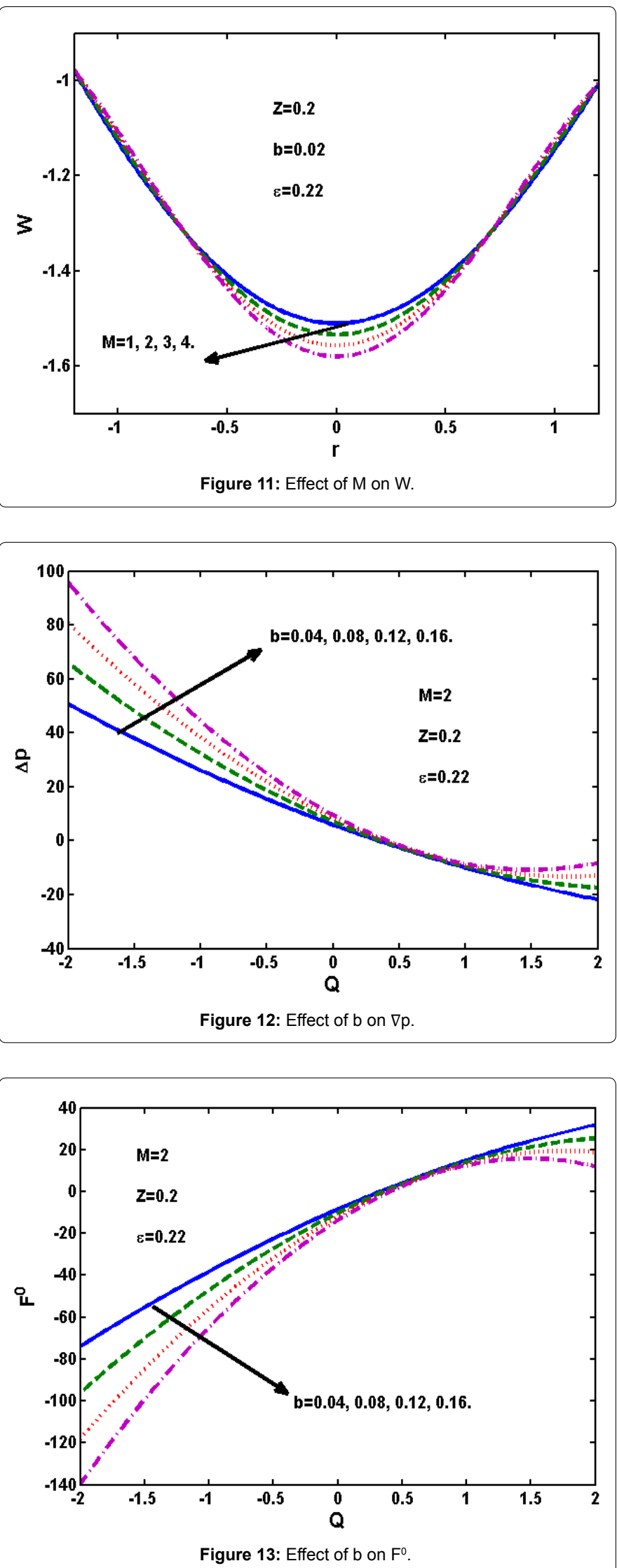


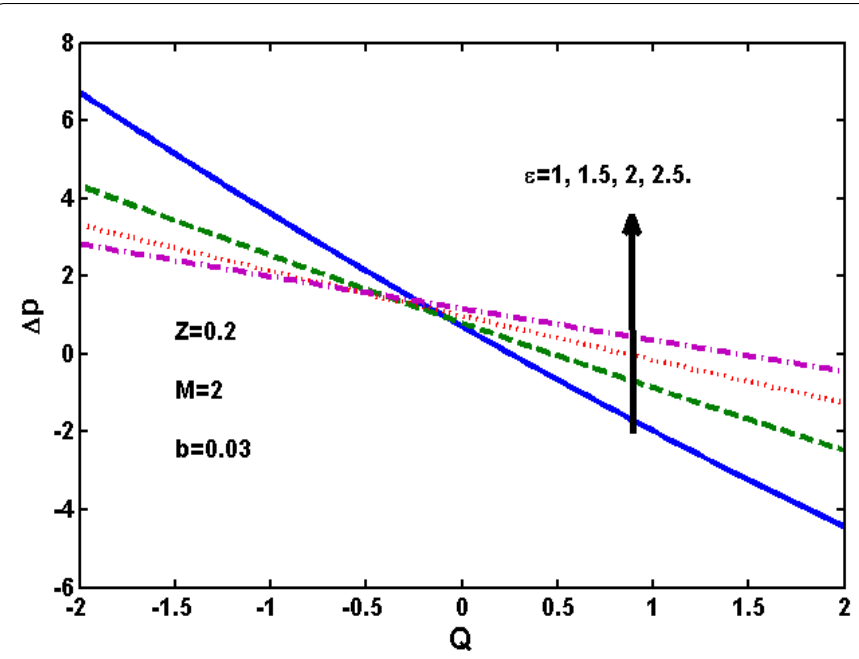

Figure 14: Effect of $\varepsilon$ on $\nabla p$
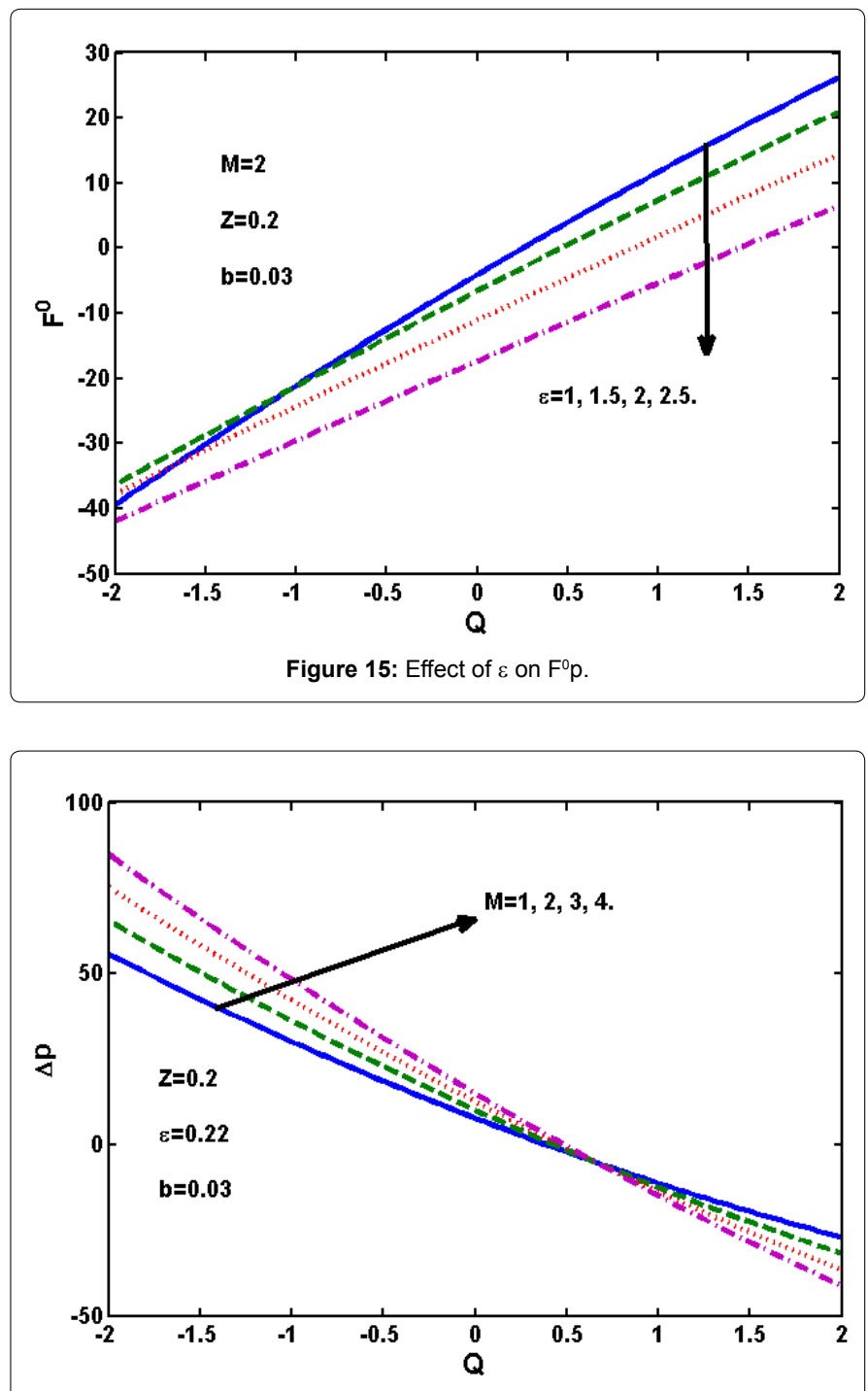

Figure 16: Effect of $M$ on $\nabla p$.
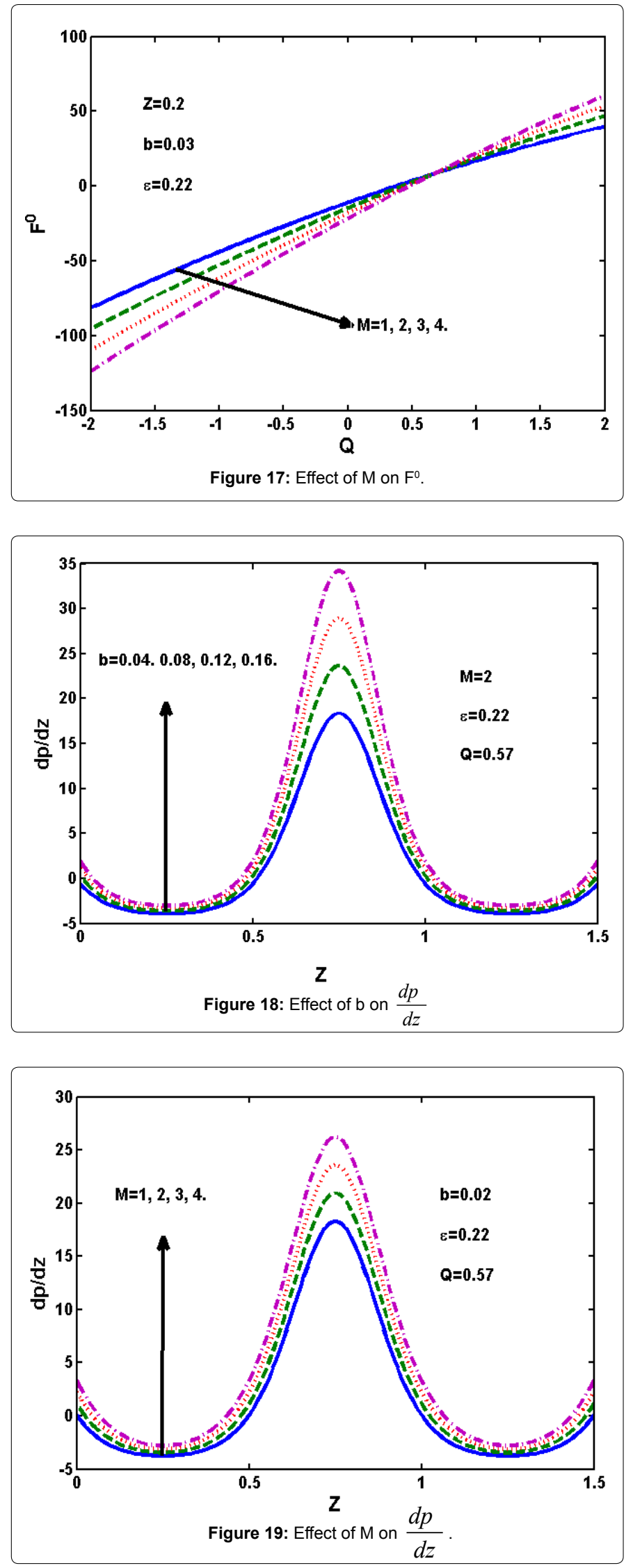
Figures 21-23 show that the behavior for different values of by considering the multisinusoidal wave, trapezoidal. Figures 24 and 25, it is depicted that by increasing value of $b, M$ pressure rise increasing. Figures 26-29 illustrate the streamlines for different wave shapes. It is distinguish that the streamlines of the flow are affected in a related behavior by increasing the value of $\in$. In fact it is pragmatic that the strength of trapped bolus appear in the wider part of the tube decreases by increasing the value of $\in$.

\section{Conclusion}

We have analyzed the peristaltic flow of non-Newtonian Sisko fluid with convective boundary conditions in a uniform tube. The viscous dissipation effects are also taken into account.

The main outcome of the present study is concisely as follows:

- Exact solution is premeditated for concentration field and temperature profile,
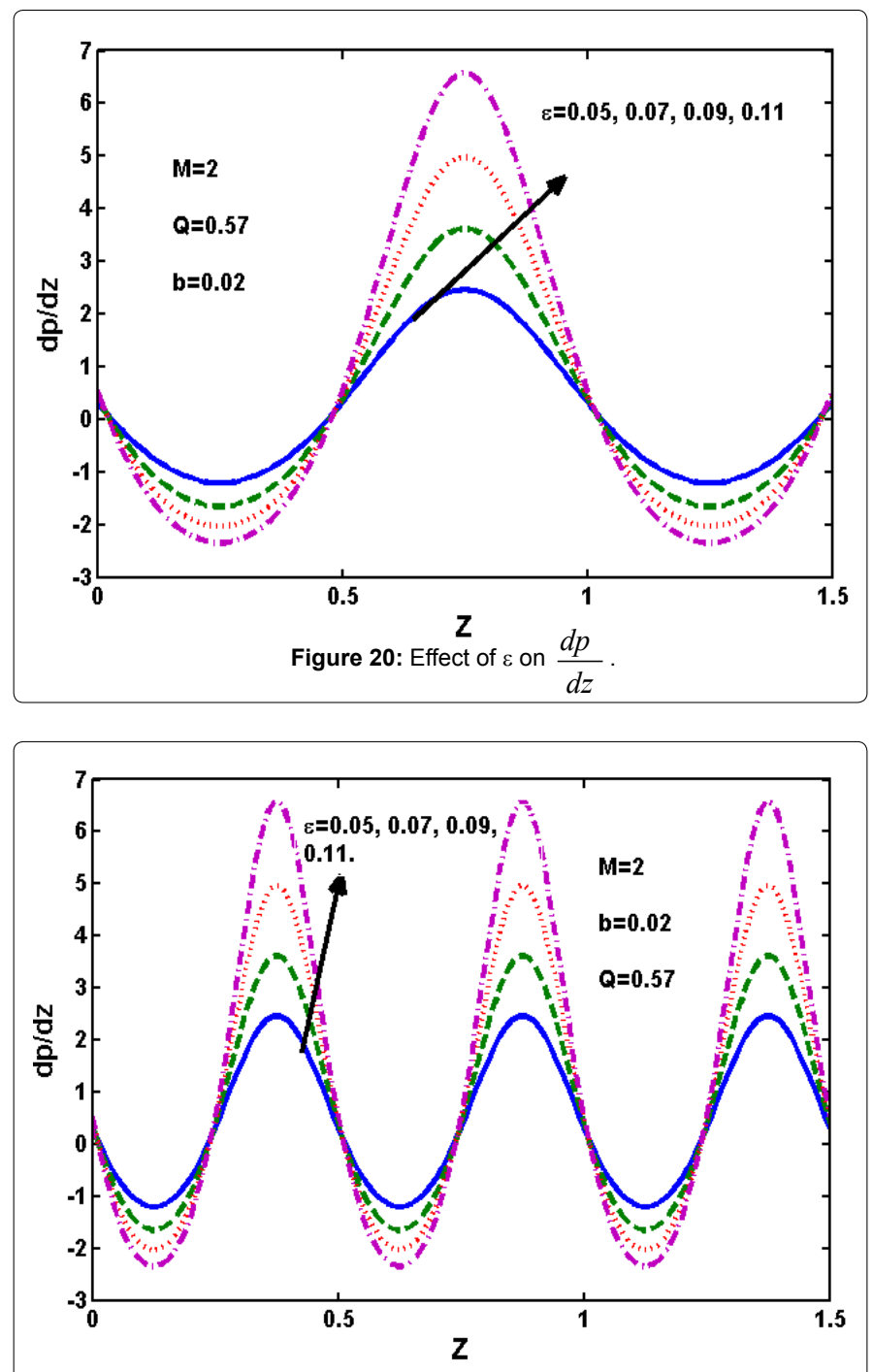

Figure 21: Effect of Mulltisinousoidal wave.

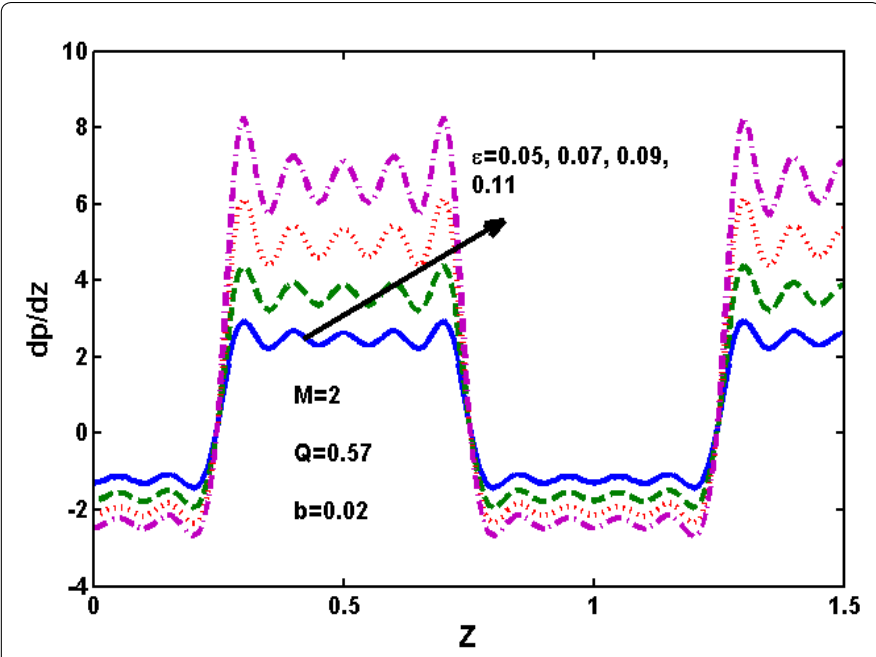

Figure 22: Effect of Square wave.

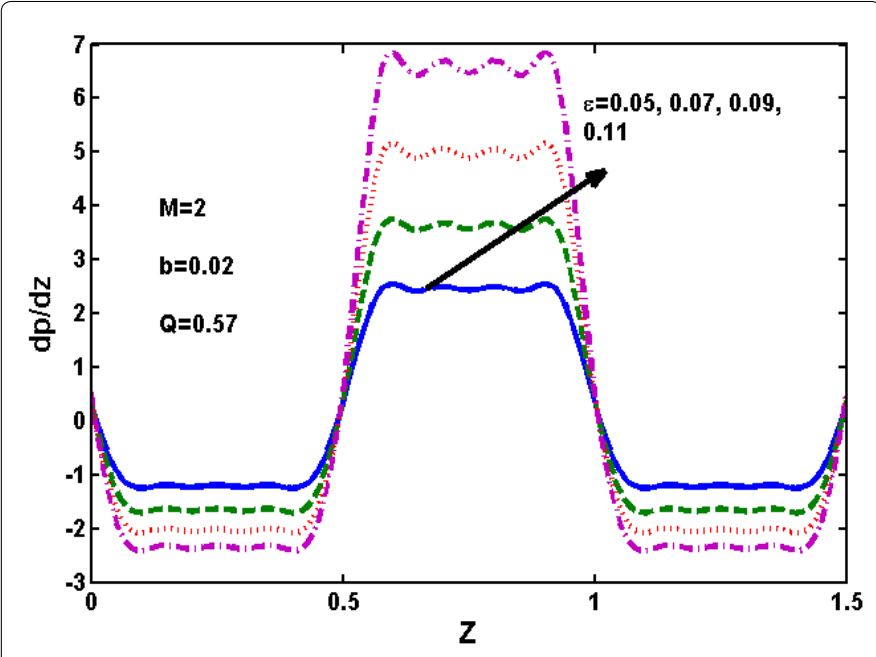

Figure 23: Effect of Trapezoidal wave.

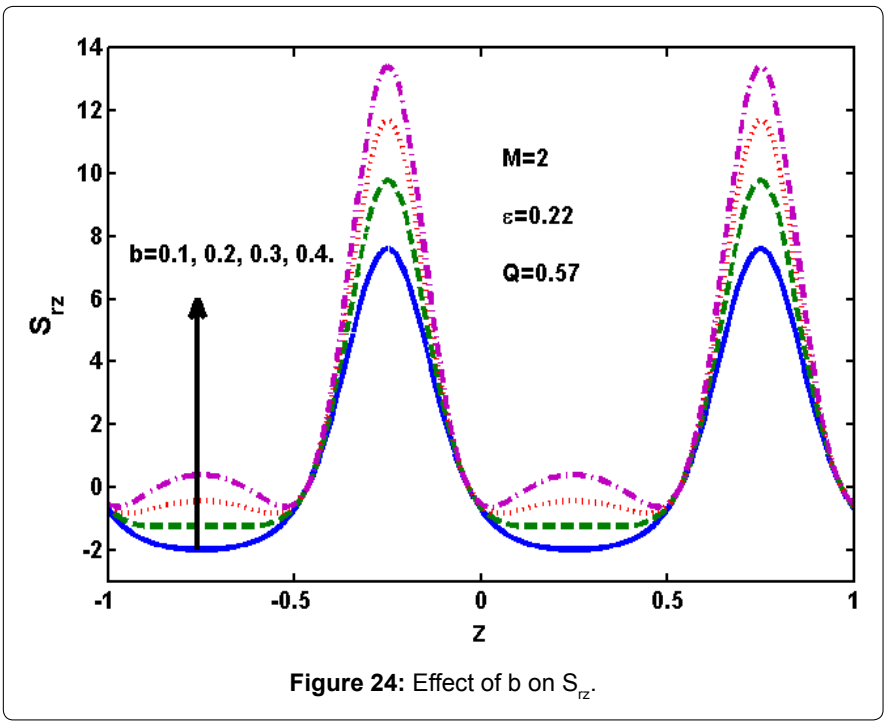


Citation: Shaheen A, Asjad MI (2018) Peristaltic Flow of a Sisko Fluid over a Convectively Heated Surface with Viscous Dissipation. J Appl Computat Math 7: 402. doi: 10.4172/2168-9679.1000402

Page 8 of 9

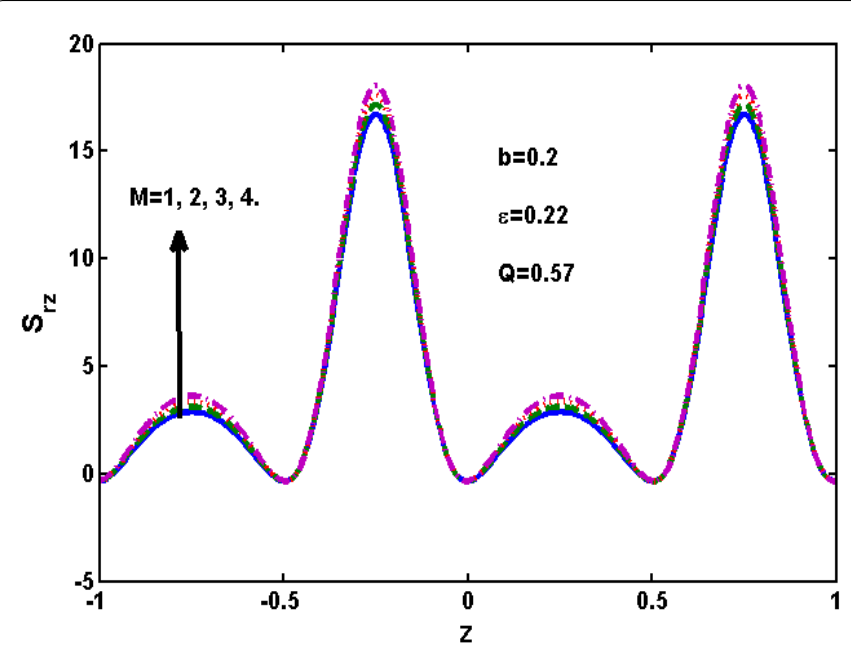

Figure 25: Effect of $M$ on $S_{r z}$.

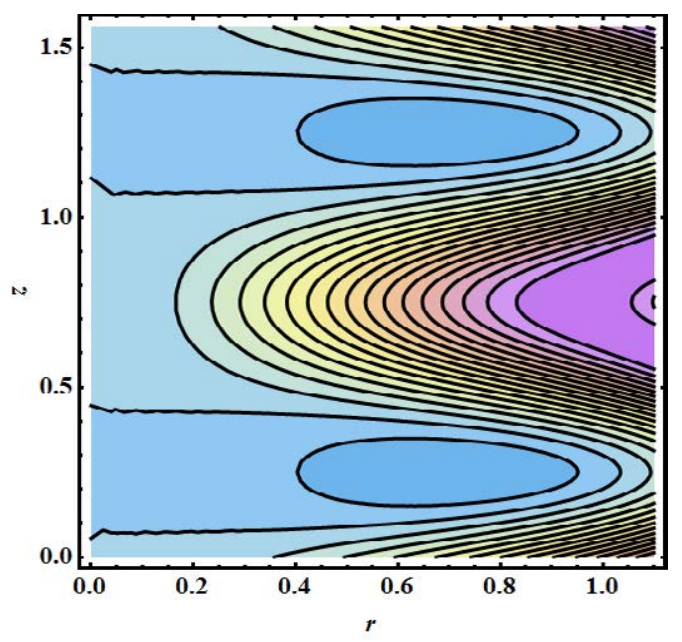

Figure 26: Streamlines for sinusoidal.

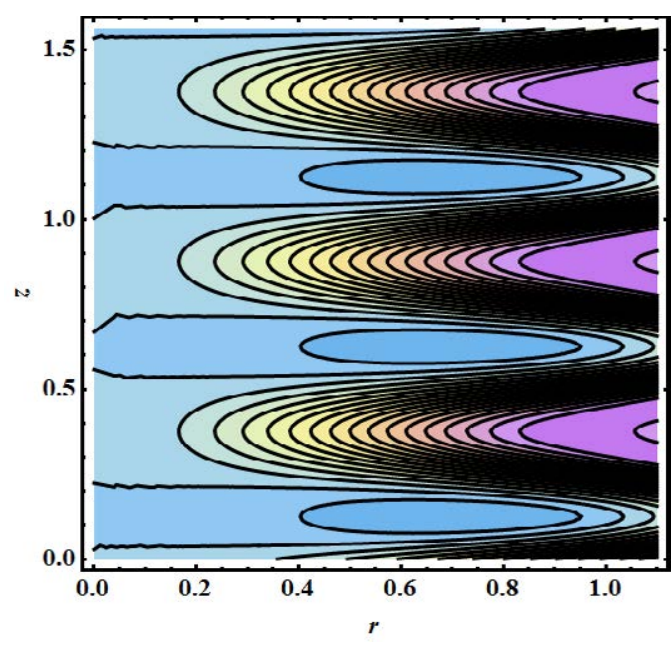

Figure 27: Streamlines for multisinusoidal.

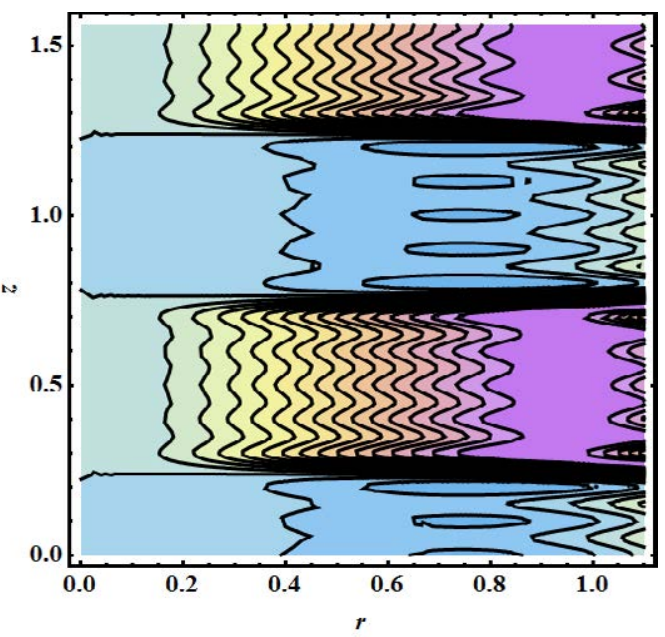

Figure 28: Streamlines for square wave.

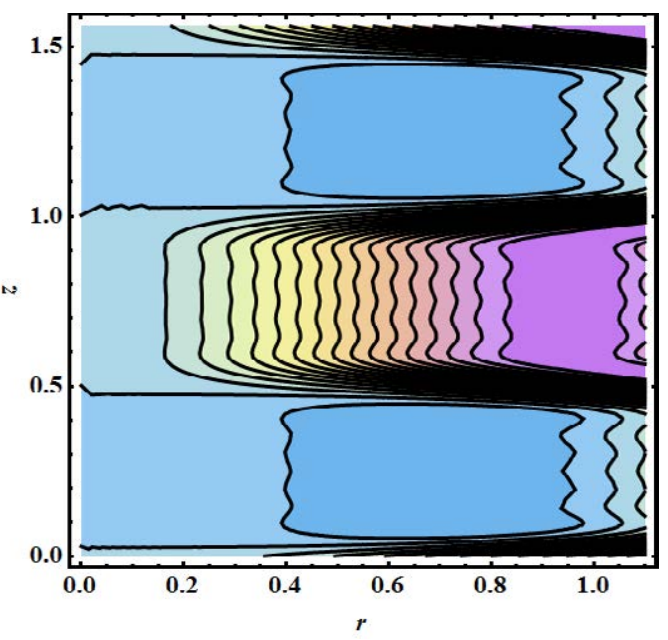

Figure 29: Streamlines for trapezoidal wave.

- The temperature profile is enhanced corresponding to increasing values of parameters $b, M, B_{k}$ and decreases by increasing the values of $\kappa$,

- The concentration field is increases by increasing the values of $b, M, B_{k}$ and decreases by increasing the values of $S_{H^{\prime}}$

- The pressure gradient increases with the increasing value of $b, M$,

There is an opposite behavior between pressure rise and the frictional forces.

\section{References}

1. Pozrikidis C (1987) A study of peristaltic flow. J Fluid Mech 180: 515-527.

2. Eytan O, David E (1999) Analysis of intra-uterine fluid motion induced by uterine contractions. Bull. Math. Biol. 61: 221-238.

3. Nadeem S, Akbar NS (2010) Influence of heat transfer on peristaltic transport of a Johnson-Segalman fluid in an inclined asymmetric channel. Commun Nonlinear Sci Numer Simul 15: 2860-2877.

4. Naseer M, Malik MY, Nadeem S, Rehman A (2014) The boundary layer flow of hyperbolic tangent fluid over a vertical exponentially stretching cylinder. Alexandria Eng J 53: 747-750. 
Citation: Shaheen A, Asjad MI (2018) Peristaltic Flow of a Sisko Fluid over a Convectively Heated Surface with Viscous Dissipation. J Appl Computat Math 7: 402. doi: 10.4172/2168-9679.1000402

5. Jaffrin MY, Shapiro AH (1971) Peristaltic pumping. Annu Rev Fluid Mech 3: 13-37.

6. Srinivas S, Gayathri R, Kothandapani M (2009) The influence of slip conditions wall properties and heat transfer on MHD peristaltic transport. Comput Phys Commun 180: 2115-2122,

7. Gupta BB, Seshadri V (1976) Peristaltic pumping in non-uniform tubes. J Biomech 9:105-109.

8. Guha SK, Kaur H, Ahmed AM (1975) Mechanics of spermatic fluid transport in the vas deferens. J Med Biol Eng 13: 518-522.

9. Batra SK (1974) Sperm transport through vas deferens: Review of hypotheses and suggestions for a quantitative model. Int J Fertil Steril 25: 186-202.

10. Hayat T, Ali N (2007) A mathematical description of peristaltic hydromagnetic flow in a tube. Appl Math Comput 188:1491-1502.

11. Hakeem AE, Naby AE, Misiery AEM, Shamy IIE (2003) Hydromagnetic flow of fluid with variable viscosity in a uniform tube with peristalsis. J Phys A Math Gen 36: 8535

12. Nadeem S, Akbar NS (2009) Influence of heat transfer on a peristaltic transport of Herschel-Bullkely fluid in a non-uniform inclined tube. Commun Nonlinear Sci Numer Simul 14: 4100-4113.

13. Vajravelu K, Sreenadh S, Babu VR (2005) Peristaltic transport of a HerschelBullkely fluid in an inclined tube. Int $\mathrm{J}$ Non Linear Mech 40: 83-90.

14. Meyer JP, Mckrell TJ, Grote K (2013) The influence of multi walled carbon nanotubes on single phase heat transfer and pressure drop characteristics in the transitional flow regime of smooth tubes. Int J Heat Mass Transf 58: 597609

15. Elsayed MA, Emam TG, Abdelgaber KM (2012) Effects of thermal radiation and magnetic field on unsteady mixed convection flow and heat transfer ove an exponentially stretching surface with suction in the presence of internal heat generation/absorption. Journal of the Egyptian Mathematical Society 20:215222.

16. Mekheimer KS (2008) Effect of the induced magnetic field on peristaltic flow of a couple stress fluid. Phys Lett A 372: 4271-4278.

17. Mekheimer KhS (2004) Peristaltic flow of blood under effect of a magnetic field in a nonuniform channels. Appl Math Comput 153: 763-777.

18. Chatterjee D, Ray S (2014) MHD mixed convection in a lid driven cavity including heat conducting circular solid object and corner heaters with Joule heating. INT COMMUN HEAT MASS. 57:200-207.

19. Ali N, Hayat T, Asghar S (2009) Peristaltic flow of a Maxwell fluid in a channel with compliant walls. Chaos Solitons Fractals 39: 407-416.

20. Sreenivasulu B, Srinivas B (2015) Mixed convection heat transfer from a spheroid to a Newtonian fluid. Int J Therm Sci 87:1-18.
21. Chen $\mathrm{CH}$ (2009) Magnetohydrodynamic mixed convection of a power law fluid past as tretching surface in the presence of thermal radiation and internal heat generation absorption. Int J Non Linear Mech 44: 596-603.

22. Choudhary MK, Chaudhary S, Sharma R (2015) Unsteady MHD flow and heat transfer over a stretching permeable surface with suction or injection. Procedia Eng 127: 703-710.

23. Muthuraj R, Srinivas S (2010) Mixed convective heat and mass transfer in a vertical channel with traveling thermal waves and porous medium. Comput Math Appl 59: 3516-3528.

24. Pal D, Mondal H (2014) Effects of temperature dependent viscosity and variable thermal conductivity on MHD non-Darcy mixed convective diffusion of species over a stretching sheet. Appl Math Model 22: 123-133.

25. Fadzilah M, Nazar R, Arifin M, Pop I (2011) MHD Boundary layer flow and hea transfer over a stretching sheet with induced magnetic field. Heat Mass Trans $47: 155-162$

26. Ishak A, Naza R, and Pop I (2009) Heat transfer over an unsteady stretching permeable surface with prescribed wall temperature. Real World Appl 10: 2909-2913.

27. Choi SUS (1993) Enhancing thermal conductivity of fluids with nanoparticles developments and applications of non-Newtonian flows. Argonne National Laboratory 66: 99-105.

28. Akbar NS, Nadeem S (2011) Endoscopic effects on peristaltic flow of a nanofluid. Commun Theor Phys 56: 761.

29. Akbar NS, Nadeem S (2012) Thermal and velocity slip effects on the peristaltic flow of a six-constant Jeffrey fluid model. Int J Heat Mass Transfer 55: 3964 3970.

30. Elsayed MA, Elbashbeshy, Aldawody AD (2010) Heat transfer over an unsteady stretching surface with variable heat flux in the presence of a heat source or sink. Computers and Mathematics with Applications 60: 2806-2811.

31. Akbar NS, Butt AW (2016) Bio mathematical venture for the metallic nanoparticles due to ciliary motion. Computer Methods and Programs in Biomedicine $134: 43-51$.

32. Akbar NS, Raza M, Ellahi R (2016) Copper oxide nanoparticles analysis with water as base fluid for peristaltic flow in permeable tube with heat transfer Computer Methods and Programs in Biomedicine 130: 22-30 .

33. Akbar NS, Tripathi D, Anwar O, Khan ZH (2016) MHD dissipative flow and heat transfer of Casson fluids due to metachronal wave propulsion of beating cilia with thermal and velocity slip effects under an oblique magnetic field. Acta Astronaut. 128: 1-12.

34. Nadeem S, Akbar NS (2010) Effects of temperature dependent viscosity on peristaltic flow of a Jeffrey six-constant fluid in a non-uniform vertical tube. Commun Nonlinear Sci Numer Simul 15: 3950-3964. 